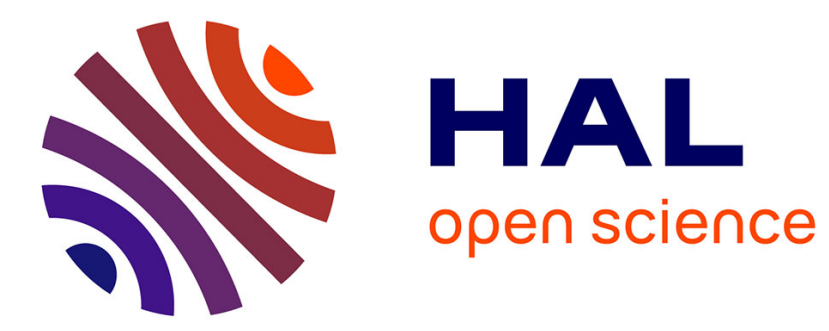

\title{
Organophosphorus derivatives for electronic devices
}

\author{
D. Joly, Pierre-Antoine Bouit, M. Hissler
}

\section{To cite this version:}

D. Joly, Pierre-Antoine Bouit, M. Hissler. Organophosphorus derivatives for electronic devices. Journal of Materials Chemistry C, 2016, 4 (17), pp.3686-3698. 10.1039/C6TC00590J . hal-01292753

HAL Id: hal-01292753

https://hal-univ-rennes1.archives-ouvertes.fr/hal-01292753

Submitted on 5 Apr 2016

HAL is a multi-disciplinary open access archive for the deposit and dissemination of scientific research documents, whether they are published or not. The documents may come from teaching and research institutions in France or abroad, or from public or private research centers.
L'archive ouverte pluridisciplinaire HAL, est destinée au dépôt et à la diffusion de documents scientifiques de niveau recherche, publiés ou non, émanant des établissements d'enseignement et de recherche français ou étrangers, des laboratoires publics ou privés. 


\section{Journal Name}

\section{ARTICLE}

\section{Organophosphorus derivatives for electronic devices}

Received 00th January 20xx, Accepted 00th January 20xx

DOI: $10.1039 / \times 0 \times x 00000 x$

www.rsc.org/

\author{
D. Joly, ${ }^{a}$ P.-A. Bouit, ${ }^{a}$ M. Hissler ${ }^{a^{*}}$
}

This review presents the main class of organophosphorus compounds (triaryl phosphines, phosphazenes, phospholes, phosphetes and diphosphacyclobutanes) which have been used in electronic devices (organic light-emitting diode (OLED), organic photovoltaic cell (OPV cell), dyesensitized solar cell (DSSC), organic field-effect transistors (OFET), electrochromic cells).

\section{Introduction}

Since the pioneering work of Shirakawa, Heeger and McDiarmid in the 1970 's, ${ }^{1}$ the interest for organic $\pi$ conjugated systems has grown tremendously. ${ }^{2}$ Indeed organic materials offer the possibility to process light-weight, flexible electronic devices. However, they have to satisfy a large number of technical requirements in order to be stable and efficient in the device. ${ }^{3}$ For example, materials have to give pin-hole free homogenous layer by vacuum sublimation or wet processing, to be stable under electric fields, to undergo balanced charge carrier injection from or to both electrodes, to be thermally stable... In order to satisfy all the technical requirements and obtain efficient materials with high absorption, conductivity or photoluminescence quantum yield, chemists have synthesized and studied a large amount of chemical structures which, for some of them, have been successfully used in devices. ${ }^{4}$ HOMO-LUMO gap is easily tuned by extension/modification of the $\pi$-conjugated system. Properties can be further modified by grafting lateral substituents on the backbone of conjugated systems. These side chains can, via supramolecular, steric or electronic effects, change the electronic properties but also the solubility or the solid-state packing. ${ }^{5}$ The insertion of heteroelement into the backbone also appeared as an appealing way to tune the properties of the materials. Heterocycles like thiophene, pyrrole and all their derivatives are now widely used to modify chemical and physical properties of $\pi$-conjugated systems. ${ }^{2}$ Interestingly, while the organophosphorus derivatives have been investigated for decades, their insertion into devices has been recently achieved. ${ }^{6,7}$ Phosphorus has been named from the ancient greek phos ("light") and phorus ("bringing") due to the intense light emitted by white phosphorus $\left(P_{4}\right)$. It is ironic to note that the element whose name is etymologically linked

\footnotetext{
${ }^{a}$ Institut des Sciences Chimiques de Rennes, UMR6226 CNRS-Université de Rennes 1, Campus de Beaulieu, 35042 Rennes Cedex, France.

+ Footnotes relating to the title and/or authors should appear here.

Electronic Supplementary Information (ESI) available: structures of compounds mentioned in the text by abbreviations ]. See DOI: 10.1039/x0xx00000x
}

to "phosphor" and "phosphorescence" was scarcely used in the emitting devices before the beginning of this century. The high reactivity and toxicity of many P-derivatives is the main reason. The ability of the chemists to stabilize and protect the P-atom allowed the introduction of organophosphorus derivatives in opto-electronic devices.

The present article does not aim to review all the different kinds of organophosphorus based materials, ${ }^{7}$ but only those who have been inserted into electronic devices (organic lightemitting diode (OLED), organic photovoltaic cell (OPV cell), dye-sensitized solar cell (DSSC), organic field-effect transistors (OFET), electrochromic cells). Indeed, despite the interesting work on some organophosphorus $\pi$-conjugated materials like phosphalkenes $^{8}$ or diphosphenes ${ }^{9}$ none of these derivatives have ever been used in electronic device, probably because of poor stability of the $\mathrm{C}=\mathrm{P}$ and $\mathrm{P}=\mathrm{P}$ bond. Actually five types of organophosphorus material have made the cut: triaryl phosphines, phosphazenes, phospholes, phosphetes and diphosphacyclobutanes (Fig. 1). This review will mainly focus on two types of opto-electronic devices: the OLEDs where the use of P-containing material is now widely developed, and the solar cells (either OPV or DSSCs). ${ }^{10}$ The case of OFET and electrochemical cells will also be addressed but they are more particular, as only specific examples were found in the literature.

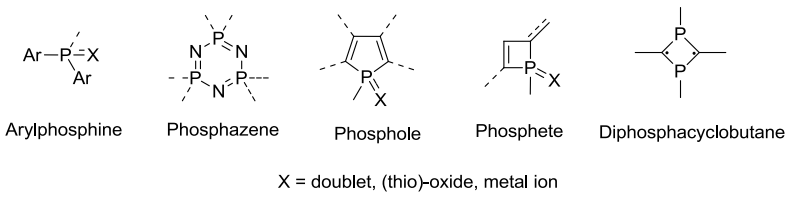

Fig. 1: Organophosphorus building blocks used in organic electronic.

\section{Phosphines}

Helped by their extensive use as ligand toward transition metal in catalysis, the aryl phosphine building block is the most studied group of organophosphorus material. It has been shown that the lone pair of $P$ is slightly involved in the delocalization within the conjugated system. ${ }^{11}$ This is due to 
the tetrahedral shape of the phosphorus and its high inversion barrier $\left(30-35 \mathrm{kcal}^{\mathrm{mol}}{ }^{-1}\right)$. Furthermore the doublet tends to quench the luminescence and these compounds rarely exhibit high fluorescence quantum yield. That is why only few examples were found of $\sigma^{3}-\lambda^{3}$ phosphine used as emitters. ${ }^{12}$ Above all, $\sigma^{3}-\lambda^{3}$ phosphines are sensitive to oxidation, which clearly alter their stability in a device. This problem is overcome by oxidizing the phosphines to its $\sigma^{4}-\lambda^{5}$ phosphines oxide analog. Even though the oxidation breaks the delocalization, their chemical stability and electronic affinity make them valuable compounds for the development of electrons transport layer (ETL) and host materials in optoelectronic. This field has been reviewed in 2012 by Jeon et al.. ${ }^{13}$ That is why only compounds leading to outstanding performances (External Quantum efficiency (EQE) > 20\%) and some of latest compounds published will be described here.

\subsection{As charge transport layer}

The role of a charge transport layer is to insure electron or hole injection and transport from the electrodes to the active layer of the device. The first study of a phosphine as charge transport layer goes back to $2001 .^{6}$ The authors showed that $\pi$-extended arylphosphines used as hole transport layer (HTL) have a better performance in OLED than its nitrogen analogs. However, their oxidized version (phosphine oxides) are mainly used for their electron transport ability as the high polarity of the $\mathrm{P}=\mathrm{O}$ group makes it electron withdrawing. In this case, the LUMO of the ETL has to be low enough to insure electron injection from the electrode. In addition, phosphine oxides are stable toward oxidation. For example, a simple triphenylphosphine oxide, $\mathrm{Ph}_{3} \mathrm{PO}$, was used in a OLED by $\mathrm{Ha}$ et al. in 2008. ${ }^{14}$ The results show that $\mathrm{Ph}_{3} \mathrm{PO}$ has great electron transport ability but also that the driving voltage for luminance output is reduced by using a $\mathrm{Ph}_{3} \mathrm{PO}$ layer over a $\mathrm{Alq}_{3}$ layer. Pyridine based phosphine oxides were also investigated. ${ }^{15}$ This family of derivatives exhibit electron transport properties and hole blocking ability due to deep HOMO levels. The association of the $\mathrm{P}=\mathrm{O}$ moiety to a pyrene (1, Fig. 2 ) able to $\pi$-stack, gives to the phosphine oxide prepared by Oyamada et al. its electron transport ability. ${ }^{16}$ Furthermore it was shown that the co-deposition of this phosphine oxide with cesium creates a charge transfer complex and enhances conductivity in the device (ITO/ $\left.\alpha-\mathrm{NPB} / \mathrm{Alq}_{3} / \mathbf{1}: \mathrm{Cs} / \mathrm{Al}\right)$ by improving electron injection at the interface with aluminum. Many spirobifluorenes based phosphine oxide analogs were developed as ETL for OLEDs. For example, 2 or $\mathbf{4}$ (Fig. 2) were used in OLED as universal ETL as they were able to reduce the driving voltage whatever the host was for the adjacent emissive layer (EML). ${ }^{17}$ The relatively high LUMO levels (-2.4 $\mathrm{eV}$ ) of this phosphine oxide makes it suitable for electron injection in any host material. Many of these spirobifluorenes were used as ETL in OLED but also as host matrix for triplet emitters in these device (see 2.2). ${ }^{18,19,20}$

A spirobenzofluorene based phosphine oxide 5 (Fig. 2) has been used as ETL in a OPV cell (ITO/PEDOT:PSS/P3HT:PCBM/5/Al) in order to improve performances (Fig. 2). ${ }^{21}$ The use of this interlayer protects the active polymer from Al diffusion into the active layer leading to higher performances, and especially better $V_{o c}$. The coordination ability of the phosphine oxide onto the Al surface leads to band bending which also explains the $V_{o c}$ improvement. Performance improvement was also observed when the LiF layer was replaced by 2 (Fig. 2). ${ }^{22}$

The structure of another universal ETL was recently published, based on arylsilyl and phosphine oxide groups (3) (Fig. 2). ${ }^{23}$ In these compounds, the Si atom breaks the conjugation. The compound thus possesses relatively high LUMO levels (-2.52 $\mathrm{eV})$ for electron injection in most host, deep HOMO levels ($6.79 \mathrm{eV}$ ) for hole blocking and high triplet energy level $\left(E_{\mathrm{T}}\right)$ ($3.36 \mathrm{eV}$ ) for triplet blocking. High EQE was achieved using $\mathbf{3}$ (Fig. 2) as ETL in blue phosphorescent OLED (PHOLED).
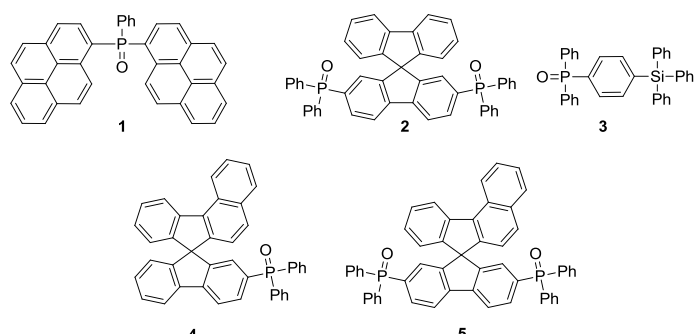

Fig. 2: Electron transport material for OLED and OPV cell.

\subsection{As matrix for phosphorescent complexes}

Designing efficient hosts for triplet emitters in OLEDs imply several requirements: in addition to the chemical and physical stability, the compound as to carry both holes and electrons (balanced charge transport) and to have suitable triplet energy level in order to transfer energy to the triplet emitter (usually an iridium complex, see supporting information). ${ }^{24}$ Following the work developed by Padmapurna et al. on ETL for OLEDs, ${ }^{6}$ phosphine oxides mainly gained interest as host matrix for triplet emitters. The $\mathrm{P}=\mathrm{O}$ moiety is used as electronwithdrawing group to ensure the electron transport in association with an electron rich group that will transport the holes (usually an amine). Furthermore, the tetrahedral shape and the lack of conjugation through the $\mathrm{P}=\mathrm{O}$ group do not affect the triplet energy of the molecule which remains high. This allows energy transfer from the host to the phosphorescent dopant. Since the first report of arylphosphine oxide as host for a blue triplet emitter in 2006 by Burrows et al., ${ }^{25}$ many derivatives were studied.

Highly efficient phosphine oxide based hosts include generally in their structure carbazole units, $\pi$-extended units (like spirobifluorene) and/or a silyl group. Due to its good hole transporting ability, the carbazole unit has been associated with a phosphine oxide, to prepare a host matrix with balanced charged transport. Substitution of carbazole by phosphine oxide units at position 2 and 7 (6) (Fig. 3) lowers the gap compared to a 3,6 substitution but even though it lowers driving voltage, ${ }^{26}$ allowing high performances with light blue triplet emitters. It also lowers $E_{\mathrm{T}}$, resulting in lower efficiency for deep blue triplet emitters. N,N'-Dicarbazolyl-3,5-benzene ( $\mathrm{mCP}$ ) modification by phosphine oxide overcomes poor electron transport and thermal stability of $\mathrm{mCP}$ while 
maintaining high $E_{\mathrm{T}} \cdot{ }^{27,28}$ Deep blue PHOLED using FCNIr were achieved with high efficiency with these two hosts. Actually 8 (Fig. 3) is one of the most efficient deep blue host for both vacuum and solution process PHOLED. ${ }^{29}$ Han et al. studied several different hosts for red, green and blue triplet emitters based on the "carbazole-phosphine oxide" approach by tuning the $\pi$-linker. ${ }^{30}$ They were able to modulate both transport properties and the $T_{1} / S_{1}$ energy level in order to efficiently transfer energy from the singlet state to triplet state of the emitter. The triphenylphosphine oxide substituted by two carbazole units (7, Fig. 3) possesses destabilized HOMO and LUMO compared to those of other hosts based also on carbazole but they retain high $E_{\mathrm{T}}$ and bipolar charge transport. 7 was found to be an efficient host for the three primary colors triplet emitters, especially for light blue Flrpic. Polymeric host based on carbazole scaffold were also studied and Shao et al. synthesized a triphenylphosphine oxide polymer with carbazole side chain, P1 (Fig. 3). ${ }^{31}$ This polymer showed balanced charge transport and high Tg. Efficiency close to $1 \%$ were achieved using single layer structure. This result was further improved to $10.8 \%$ when a hole blocking layer was inserted in the device. 1,2,4-triazole was also associated with phosphine oxide and carbazole. In order to maintain high $\mathrm{T}_{1}$ level, the carbazole was coupled in the meta position of the triazole core in $\mathbf{1 1}$ (Fig. 3). ${ }^{32}$ Sky blue emitting $\operatorname{Ir}(\mathrm{dbi})_{3}$ complex was picked as guest and high power and current efficiency of $43.0 \mathrm{Im} . \mathrm{W}^{-1}$ and $41.6 \mathrm{~cd} . \mathrm{A}^{-1}$ were obtained with a multilayer configuration. Instead of carbazole, triarylamine was also associated with phosphine oxide through a non-conjugated cyclohexyl spacer, 12 (Fig. 3). ${ }^{33}$ This design allows getting both bipolar transport and high $\mathrm{T}_{1}$ level and was therefore used as host for blue phosphorescent complex Flr6. In combination with phosphine oxide based ETL, efficiency over $20 \%$ was achieved.

Phosphine oxide substituted by spirobifluorene showed only electron transport ability and therefore exhibit significant rolloff (i.e. decrease of efficiency with increasing current density). High performances could however be achieved with some of these derivatives. ${ }^{2,7}$ Phosphine oxide substituted spirobifluorene (2, Fig. 2) was used as host for FIrpic and EQE of $20.3 \%$ was achieved and $19 \%$ was obtained without LiF injecting layer. ${ }^{34}$ In order to efficiently transfer energy from a dopant to a red triplet emitter, the $E^{\top}$ of the host should be lower than those used with blue emitters. The spirobifluorene core of $\mathbf{2}$ was thus modified to $\mathbf{5}$ (Fig. 2) resulting in a $E^{\top}$ of 2.32 $\mathrm{eV}$ against $2.83 \mathrm{eV}$ for $2 .^{35}$ Device with $\operatorname{Ir}(\mathrm{pq})_{2}$ acac as emitter and 5 as host displayed maximum EQE of $20 \%$. In 2015, Poriel et al. combined the diphenylphosphinospirobifluorene structure to the carbazole moiety to benefit the balanced charge transport given by both fragments (9, Fig. 3). ${ }^{36}$ This platform allowed the authors to prepare one of the most efficient single layer green PhOLED to date (EQE $=13.2 \%$ with $\operatorname{Ir}(\mathrm{ppy})_{3}$ as emitter).

Silyl group has also attracted attention due to the bulkiness and the non-conjugating properties of the phenylsilyl derivatives. Linked to carbazole and phosphine oxide, the tetraphenylsilyl derivatives host (10, Fig. 3) showed balanced charged transport and high $E^{\top}$ for energy transfer to deep blue phosphorescent dopant and EQE of $22 \%$ was achieved. ${ }^{37}$

In 2013, Tao et al. proposed a new approach to develop ambipolar host involving $\mathrm{N}-\mathrm{P}=\mathrm{O}$ pattern where carbazole or arylamine are bonded to the phosphine oxide (13, Fig. 3). ${ }^{38}$ The later possesses resonance structures which allow better delocalization. This established the possibility for regulating electrical processes and therefore improving charge transport and charge injection. This ability was illustrated in device using FIrpic as emitter. EQE as a high as $16.5 \%$ was obtained using 13 as host for relatively low driving voltage showing the ability of the $\mathrm{N}-\mathrm{P}=\mathrm{O}$ pattern.

In a recent paper, Lin et al. studied the phototostability of several carbazole based host with different electron deficient units. $^{39}$ It turned out that the weak C-P bond in the phosphine based host leads to high instability of the device. Such evidence of instability has not been shown for other type of Pbased host, if so it could become a major drawback to the development of device using these derivatives that chemists would have to tackle.

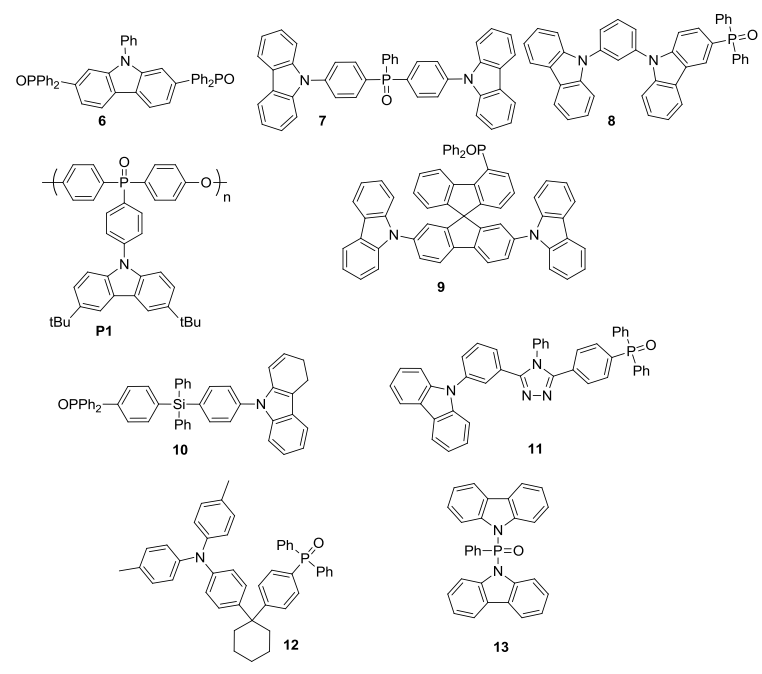

Fig. 3: Phosphine oxide based host structure for OLEDs

\subsection{As emitting materials}

The phosphine oxide pattern was also inserted into the backbone of oligomers. This allows developing deep blue emitters due to the disruption of the conjugation. Solution processability was maintained and the pyramidal geometry prevents solid-state aggregation. This geometric parameter is an intrinsic advantage of P-derivatives for all applications linked with solid-state emission (see also 4.2).

Liu et al. synthesized different linear oligomers made of a phosphine oxide central core, oligo-phenylene/fluorene chains and N-phenylnaphthalen-1-amine end cap (P2, Fig. 4). ${ }^{40}$ These structures allowed authors to obtain balanced charge transport and deep blue emission. EQE up to $2.06 \%$ was achieved with P2 and very low efficiency roll-off. The same group later developed two-dimensional oligo-fluorenes P3 with a central phosphine oxide (Fig. 4). ${ }^{41}$ Oligomers were inserted into device with the following structure 
(ITO)/PEDOT:PSS / EML / TPBI /CsF /AI. EQE up to 3.41\% was achieved with fluorine based oligomers P3-3 (Fig. 4) with deep blue emission. It turns out that 2D oligomers works better than their 1D analogs. Following their work on polymeric host ${ }^{31}$ Wang et al. grafted phosphorescent complex (FIrPic) as side chain of the polymer backbone of $\mathbf{P 4}{ }^{42}$ The later consists of a fluorinated and non-fluorinated phosphine oxide with carbazole units (P4, Fig. 4). EQE up to $9 \%$ was achieved along with $19.0 \mathrm{~cd} . \mathrm{A}^{-1}$ luminous efficiency. In a further work, Shao et al. introduced an additional yellow phosphorescent emitter on the side chains in order to obtain white OLED (Fig. 4). ${ }^{43}$ This approach is possible since the polymer backbone possess a high triplet energy making energy transfer from the backbone to the blue triplet emitter effective. The performances obtained are among the best for single polymer white OLED. Another approach to obtain a white emission is to generate exciplex. ${ }^{44}$ In Qiu's work, a novel electro-deficient compound based on an anthracene diphenylphosphine oxide 15 (Fig. 4) forms exciplex at the interface with NPB where excitons are recombining. This phenomenon was also observable in a blend of 15 and NPB. As a result, pure white emission (CIE: $x, 0.33$; $y$, 0.33) was obtained with a simple bilayer structure (ITO/NPB/15/Mg:Ag/Ag). ${ }^{21}$ Kim et al. developed an exciplex with a high triplet energy level by mixing a phosphine oxide based ETL, 14 (Fig. 4), and $\mathrm{MCP}$ as HTL. The exciplexes are formed efficiently in the host and the energy transfer from the exciplex to the blue phosphorescent dopant (FIrpic) is very efficient, enabling the triplet harvest without energy loss. As a result, blue PhOLED with high performance have been fabricated. The EQE reaches $30.3 \%$ with a maximal power efficiency of $66 \mathrm{Im} \mathrm{W}^{-1}$. 45

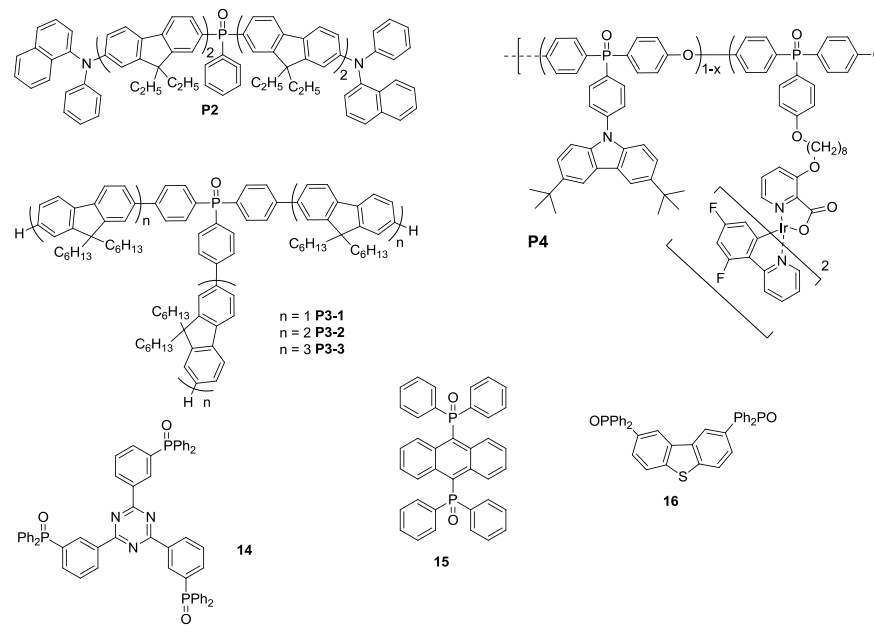

Fig. 4: Phosphine oxide based emitters for OLEDs

Finally one example of thermally activated delayed fluorescence (TADF) was reported by Adachi et al. in the exciplex state of a complex where 16 (Fig. 4) is used as electron accepting material. ${ }^{46}$ EQE of $10 \%$ was obtained. Considering the several perspectives opened by this new phenomenon for fluorescent OLEDs, molecular design of novel phosphine based TADF emitters is probably a future area of development for the phosphine based molecular materials. ${ }^{47}$

\section{PHOSPHAZENES}

Phosphazenes are organic compounds were $\mathrm{P}$ and $\mathrm{N}$ atoms are linked through a double bond. There is no evidence of conjugation in the phosphazene because these materials are ylides with highly polarized bond. Phosphazenes have been well studied in both linear and cyclic forms due to their various properties including excellent hydrolytic stability, flame retardant properties, thermal stability and liquid crystalline behavior among others. The phosphazenes have been inserted in DSSC and OLEDs. Cyclic phosphazenes are used as platform for the synthesis of star-shaped species for OLED applications taking advantage of their low $\mathrm{Tg}$ and high stability. Cyclic phosphazene cores possess some appealing advantage for organic electronics: they are easily functionalized and highly stable even under hard condition. The phosphazene core is "electronically" inert: the electronic and optical properties only come from the lateral $\pi$-conjugated system. The resulting compounds exhibit spherical shapes which lead to amorphous solid phase, an important property for OLED applications.

\subsection{As electrolyte for DSSC}

Polyphosphazene first caught the attention for lithium-ion battery applications ${ }^{48}$ due to their ability to conduct efficiently lithium and their high thermal stability. They were then used as electrolyte for quasi-solid state or solid-state DSSC. In 2009, Xiang et al. reported an electrolyte based on two polymers: polyphosphazene with propionitrile and iodo-(ethylene oxideco-propylene oxide) side chains (Fig 5), and oligoorganosiloxane grafting oligo-ethylene oxide and propylene oxide dimethylamine side chains. ${ }^{49}$ The low $\mathrm{Tg}$ of both polymers enables deep penetration into the pores of the $\mathrm{TiO}_{2}$ nanoparticles. The cross linking precursors on the side chains undergo a quaternization reaction upon thermal treatment making the electrolyte insoluble. Photoconversion efficiency with this electrolyte reached $2.66 \%$ upon doping with 20 wt\% modified silica nanoparticles. In the early 2010s, the group of Allcock et al. studied the pores penetration ${ }^{50}$ and the influence of iodide salt ${ }^{51}$ of linear and cyclic phosphazene based non-volatile electrolytes. They showed that much alike other polymers, polyphosphazene face pore penetration issues that could partly be overcome with a heat-fluidization and solvent assistance. As a result, the use of smaller oligomers or cyclic phosphazene is preferable to facilitate infiltration. Performances obtained with this electrolyte remain low; their structure was probably not fully adapted to ionic transport in DSSC as they were initially designed for lithium-ion batteries. Nevertheless, molecular engineering of the side arm could lead to better results.

\subsection{As emitters}

Bolink et al. functionalized the phosphazene core with fluorescents (17-20, Fig. 5) or phosphorescents moieties (21, Fig. 5). ${ }^{52}$ The compounds exhibited high $T_{\mathrm{d}}$, high $T_{\mathrm{g}}$ without any $\mathrm{T}_{\mathrm{m}}$ confirming the amorphous nature. They showed blue-green emission in solution and in film. Single layer OLEDs 
(ITO/PEDOT:PSS/17(18-20)/Ba:Ag) led to low performances but showed that the fluorescent derivatives only had hole transport character due to the high numbers of triarylamine groups. In order to overcome such unbalanced charge transport, an ETL (TPBI) was used to give the following device configuration

(ITO/PEDOT:PSS/17(18-20)/TPBI/Ba:Ag). Emission ranging from blue for compounds $\mathbf{1 7}$ and 18, to green for larger compounds $\mathbf{1 9}$ and $\mathbf{2 0}$ was observed. Best performances were achieved with cyclic phosphazene (CP) 17, reaching $11000 \mathrm{~cd} . \mathrm{m}^{-2}$ at $12 \mathrm{~V}$ and an EQE of $0.72 \%$ at $8 \mathrm{~V}$ ). In the case of phosphorescent derivative $\mathbf{2 1}$, a matrix of PVK and PBD was employed to dilute the compound. The diode with the following structure ITO/PEDOT/PSS/PVK:PBD:21/TPBI/Ba/Si had an EQE of 7\%. L. Bauge et al have developed several series of phosphoruscontaining dendrimers decorated with fluorescent end groups (naphthalene, anthracene and pyrene). In thin films, the pyrene based dendrimers exhibit a very broad emission characteristic of excimers. OLED including an emitting layer based on a $4^{\text {th }}$ generation dendrimer including 48 pyrenes units, 24-G4 (Fig. 5) in a PVK matrix has been fabricated. The electroluminescence spectrum presents the characteristic emission of the pyrene excimers but the emission of light is low $\left(3.5 \mathrm{~cd} / \mathrm{m}^{2}\right)$ and the threshold voltage is high (over 20V). ${ }^{53}$

\subsection{As host matrix for triplet emitters}

As in phosphine oxides, the absence of conjugation and the resultant high HOMO-LUMO gap added to high glass transition temperature make CP interesting hosts for phosphorescent derivatives. In that context, two different teams designed solution processed and vacuum processed $\mathrm{CPs}^{54,55}$ Soh et al. developed CP derivative $\mathbf{2 2}$ based on carbazole. No melting or crystallization points were observed showing that these materials are highly amorphous. The triplet energy band gaps of the two CPs were estimated at $3.0 \mathrm{eV}$ which is higher than triplet level of the blue emitters (FIrpic) (2.62 eV). The following OLED structure was employed to evaluate the host abilities of the CPs: ITO/PEDOT:PSS/poly-TPD/8:emitter /BCP/BCP: $\mathrm{Cs}_{2} \mathrm{CO}_{3} / \mathrm{Al}$. A green emitter $\left(\operatorname{Ir}(\mathrm{mppy})_{3}\right)$ and FIrpic were used in this case. Devices showed high luminance and power efficiency, twice better than reference device using PVK as host. Recently Schrögel et al. prepared a vacuum processable CP $\mathbf{2 3}$ host for deep blue triplet emitter. Thermal analysis showed that the CPs has high $T_{\mathrm{d}}$ and moderate $T_{\mathrm{g}}$. Furthermore, morphologically stable amorphous films could be obtained from both solution and vacuum process. Single carrier device made from $\mathbf{2 3}$ showed that it has balanced charge transport properties. The triplet energy level of the CP was calculated at $-\mathbf{3 . 2} \mathrm{eV}$ and therefore $\mathbf{2 3}$ was used as host for deep blue triplet emitter $(\operatorname{Ir}(\mathrm{dbfmi}))$ in an OLED with the following structure ITO/MoO $\mathrm{MOND}_{3}$ NDPBIC/DPBIC:Ir(dbfmi) /23:Ir(dbfmi)/DBFSi/TPBi/LiF/Al. The peak of power efficiency of $7.6 \mathrm{Im} . \mathrm{W}^{-1}$ is achieved at $5.5 \mathrm{~V}$ as the maximum luminance of $5000 \mathrm{~cd} . \mathrm{m}^{-2}$ is reached at $13.5 \mathrm{~V}$. These values are significantly lower than those obtain with other hosts ${ }^{56}$ but this remains a proof of the flexibility of CPs which can be either processed by solution or vacuum.

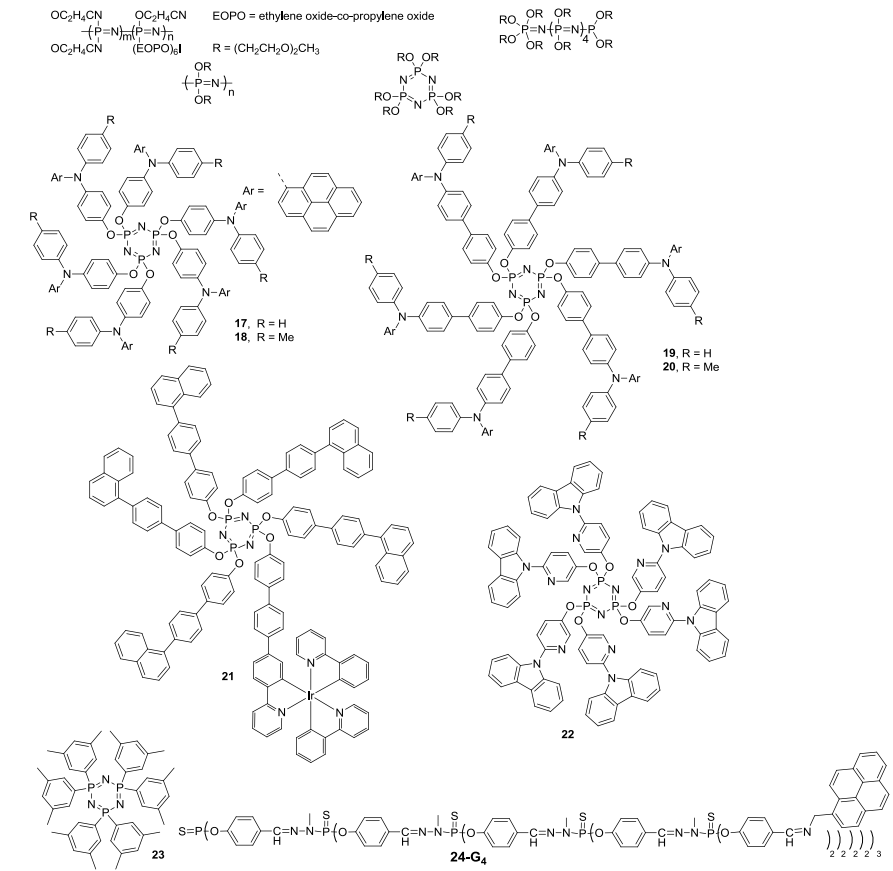

Fig. 5: Phosphazene derivatives used in electrolyte for DSCs, Fluorescent and phosphorescent CPs 3-7, 13-G4 and CP host 9 and 10.

\section{PHOSPHOLES}

Phospholes are a particular class of phosphines in which the Patom is incorporated in an unsaturated 5-membered heterocycle. Unlike thiophene and pyrrole, 1-phenylphosphole is only slightly aromatic as the phosphorus lone pair does not participate in the intracyclic delocalization. ${ }^{57}$ Actually its low aromaticity comes from the interaction between the exocyclic $\sigma^{*}(\mathrm{P}-\mathrm{R})$ and the intracyclic dienic moiety. The lone pair of the phosphole is thus available for reactivity. In the case of $\sigma^{4}-\lambda^{5}$ phospholes oxide $(\mathrm{P}=\mathrm{O})$ or thio-oxide $(\mathrm{P}=\mathrm{S})$, the compounds become slightly antiaromatic. ${ }^{58}$ These unusual electronic properties allowed to access compounds with rather low HOMO-LUMO gap. Furthermore, as already mentioned for phosphines, the pyramidal shape of the P-atom affords significant steric hindrance that prevents solid-state aggregation.

\subsection{As charge transport layer}

Benzophospholes (BP) 25-26 (Fig. 6) were developed by Tsuji et al. as ETL for OLEDs. ${ }^{59} \mathbf{2 5}$ and $\mathbf{2 6}$, which only differs by the substituent at the $\mathrm{P}$-atoms ( $\mathrm{O}$ vs $\mathrm{S}$ ), possess very similar physical and photophysical properties. They showed a highly stable amorphous phase due to the tetrahedral shape of the Patom preventing formation of microcrystalline domains. They also have an average to good electron mobility, $5.10^{-6} \mathrm{~cm}^{2} . V^{-}$ ${ }^{1} . \mathrm{s}^{-1}$ for 25 and $2.10^{-3} \mathrm{~cm}^{2} . \mathrm{V}^{-1} \cdot \mathrm{s}^{-1}$ for 26 . This difference is explained by the highly polar character of the $\mathrm{P}=\mathrm{O}$ bond which trap electrons. They were therefore used as dopant in a CS ETL which was incorporated in an OLED. The device including benzophosphole $\mathbf{2 6}$ showed slightly superior performances than the one based on 25 as the voltage at $1000 \mathrm{~cd} . \mathrm{m}^{-2}$ was $5.0 \mathrm{~V}$ and $5.9 \mathrm{~V}$ and luminance efficiency was $1.8 \mathrm{Im} . \mathrm{W}^{-1}$ and 1.4 $\mathrm{Im} . \mathrm{W}^{-1}$ respectively. 
Similar properties were observed with benzophosphole $\mathbf{2 7}$ (Fig. 6) which were used as cathode buffer layer along with 25 and 26 in an OPV cell (ITO/PEDOT:PSS/BP/PB:SIMEF/27/AI). ${ }^{60}$ The high glass transition observed for these compounds allows thermal annealing process without altering the layer. This process improves the power conversion efficiency (PCE) of the solar cell from 2.9 to $4.6 \%$. Authors claim that coordination complexes are formed at the interface with Aluminum, like for phosphine oxide, resulting in lower resistance between the two layers. Inspired by this work, Matano et al. developed diarylaceneoxophospholes 28-31 (Fig. 6) exhibiting relatively high $\mathrm{Tg}$ and modest mobilities. ${ }^{61}$ Nevertheless their use in OPV cells as buffer layer (ITO/PEDOT:PSS/P3HT:IC 70 BA/28-31/AI) gave better performances than with $B C P$, a common organic $n-$ type material. Authors report that the nature of the 2,5substituents of the phosphole ring impacts the performances due to different packing motifs and/or different contact resistance. In this case, oxophosphole worked significantly better than their thiooxo-counterparts.
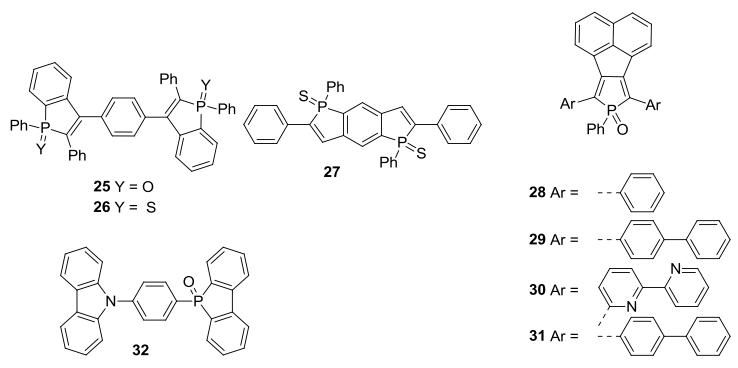

Fig. 6: Electron transport material for OLED and OPV.

One example of dibenzophosphole based host for triplet emitters was published in 2012 (32, Fig. 7). ${ }^{62}$ The author prepared an OLED with a Os(II) based emitter presenting an EQE of $14 \%$ which is $3 \%$ higher than the reference device containing a CBP host. This effect was attributed to the better charge carrier mobility (both for holes and electron) of $\mathbf{3 2}$ compared to BCP.

\subsection{As emitters in OLED}

The insertion of phosphole derivatives as emitters in OLED goes back to 2003 by Fave et al. with 2,5-dithienylphosphole derivatives 33-34 (Fig. 7). ${ }^{63}$ Derivatization can be performed on the reactive $\mathrm{P}$-center to obtain either thiooxophospholes or $\mathrm{Au}(\mathrm{I})$ complexes. Several other phosphole-based conjugated systems were prepared and inserted in fluorescent OLEDs. ${ }^{64}$ Along these studies, the only $\sigma^{3}-\lambda^{3}$ phosphole suitable for vacuum sublimation was $\mathbf{3 5}$ (Fig. 7) as these species are usually not thermally stable enough to stand this process. Green emission at $510 \mathrm{~nm}$ was obtained with EQE of $0.08 \%$ in single layer OLED $(0.29 \%$ in a multilayer configuration). Thiooxophosphole derivatives 33, 36, 37 (Fig. 7) showed low performances in single layer OLED but they can be improved by using HTL ( $\alpha-N P B)$ and ETL $\left(\mathrm{Alq}_{3}\right)$. Quantum efficiency can be increased by four to ten times depending on the structure of $\pi$-conjugated systems. For example, maximum EQE of emitters 33 goes from $0.16 \%$ to $0.80 \%$. Interestingly, gold complexes 34 or 38 (Fig. 7) have very low performances in single layer diodes. Furthermore, electroluminescence differ completely from photoluminescence in solution, unlike $\sigma^{3}-\lambda^{3}$ phosphole and thiooxophosphole. This phenomenon was later rationalized by Joly et al. on fluorenylphosphole 39-43 (Fig. 7). ${ }^{65}$ They unambiguously showed that the lower energy emission was actually coming from fast decomposition of the gold complexes upon electric field. Some low molecular weight dibenzophospholes were inserted in OLED by vacuum sublimation without success as the devices characteristics show instability with increasing driving current. ${ }^{65}$ On the contrary, polymers based on fluorene and benzophosphole P5 / benzooxophosphole P6, Fig. 7) were used as EML in single layer device (ITO/PEDOT:PSS/EML/AI). ${ }^{66}$ P5 showed blue electroluminescence with brightness up to $1423 \mathrm{~cd} . \mathrm{m}^{-2}$ whereas P6 exhibited a white emission but with lower brightness (142 cd. $\mathrm{m}^{-2}$ ).

So far, the best EQE recorded for an OLED with EML only based on phosphole derivative has been $1.8 \%$ with 2,5difluorenylthiooxophosphole 41 (Fig. 7). In 2012, Kondo et al. reached $4.0 \%$ EQE which is close to the theoretical limit of fluorescent OLEDs, using dithienophosphole dopant 45 as emitter in a TBADN host. ${ }^{67} \mathrm{~A}$ new type of phosphole basedemitter was developed by Chen et al. using benzofuran fused phosphole 46. EQE in multilayer device was only $0.45 \%$, limited by the poor transport properties of the phosphole and probable electromers formation as the electroluminescence was red shifted by $40 \mathrm{~nm}$ compared to neat film photoluminescence.

Phosphole emitters also appeared as original material in the context of white light emission, which remain a challenge for both academic and industrial purposes. To this end, orange emitting phospholes were chosen as dopant for blue emitting matrixes in order to achieve white light through energy transfer. Preliminary work was done by Fadhel et al. with 2,5dithienylphosphole 33, 34 and $\mathbf{4 7}$ (Fig. 7). ${ }^{68}$ The amount of $\mathbf{3 3}$ required to dope DPVBi to achieve a white emission was too low and therefore tricky to control. The authors thus used the HTL, $\alpha$-NPB, as matrix. A moderate increase of dopant amount allowed preparing an OLED with a satisfactory white emission (CIE: $x, 0.28 ; y, 0.34)$. Same approach was used with dopant 47. The red-shifted emission of $\mathbf{4 7}$ compared to 33, allowed to prepare a purer white OLED using a doping rate of $0.2 \%$ in $\alpha$ NPB. 43 and 44 (Fig. 7) were also used as dopant for DPVBi. ${ }^{69}$ The optimum doping rate of $\mathbf{4 3}$ was found to be $0.3 \%$ (CIE: $x$, $0.27 ; y, 0.33$ ) and EQE reached $2.1 \%$. The necessary amount of dopant $\mathbf{4 4}$ to achieve a white emission was surprisingly higher than for all other phosphole derivatives. Furthermore, it was found that this dopant was highly quench resistant as the EQE remains stable even at very doping rate. This was due to a combination of favorable factors such as structural and physical properties. A dopant based on 2,2'-bisphopshole 48 was later developed by Chen et al. ${ }^{70}$ In this family of compounds, the control of the distortion angle between the two phosphole units allowed fine-tuning of the optical/electronic properties and close to perfect $\mathrm{CIE}$ coordinate was achieved (CIE: $x, 0.34 ; y, 0.34)$ by doping a 
DPVBi matrix. Even if the working parameter of this device remain low, the proof of concept of using the torsion angle of biphosphole to adjust the HOMO-LUMO gap open very interesting perspective for every opto-electronic applications. Finally, we recently developed a new family of P-containing PAHs (compounds 49-50, Fig 7). ${ }^{71}$ These compounds were the first reported polyaromatic compounds featuring a $P$ atom in their scaffold. They show high luminescence in the orange-red region in diluted solutions and this fluorescence remains high in solid matrix. WOLED devices were prepared using NPB as blue matrix. With a doping rate of $0.8 \%$, white emission was achieved (CIE: $x, 0.32 ; y, 0.37$ ) with EQE of $1.2 \%{ }^{72}$ In this case again, efficiencies remain low but optimization on this new family of P-derivative may lead to interesting improvement in the field of emitting materials.

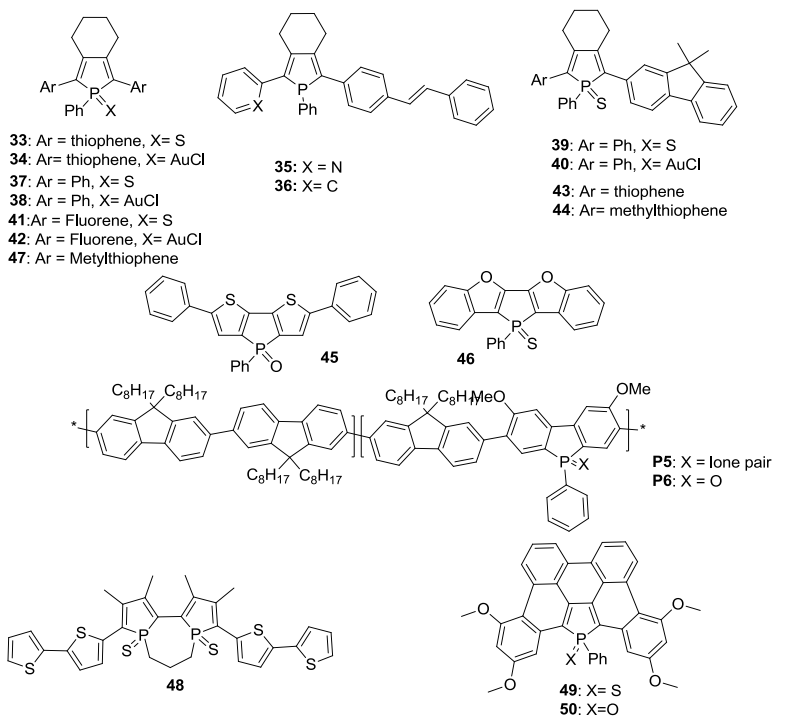

Fig. 7: Phosphole derivatives as emitters in OLED and WOLED

\subsection{As dyes in Dye-sensitized Solar Cell (DSSC)}

In 2010 Kira et al. developed a sensitizer for DSSC based on 1hydroxy-1-oxydithienophosphole derivatives 51-52 (Fig. 8), used as both acceptor moiety and anchoring group. ${ }^{73}$ The IPCE of the DSSC with $\mathrm{TiO}_{2} / \mathbf{5 1}$ and $\mathrm{TiO}_{2} / \mathbf{5 2}$ were estimated at $66 \%$ and $43 \%$, respectively. Maximal efficiency was measured for 52 with PCE of $1.8 \%$. Even if the efficiencies remain low, the originality of this work is the use of hydroxyoxophosphole moiety as binding motif toward $\mathrm{TiO}_{2}$, as most of the studies use carboxylic acid or phosphinic acid which are not detailed in this review. ${ }^{74}$

More recently, the same team developed a new series of pushpull dyes featuring a triarylamine donor and a carboxylic acidsubstituted thioxophosphole as acceptor (53-54, Fig. 8). ${ }^{75}$ In this case, the anchoring group is not located at the P-atom. The sterically hindered $\mathrm{P}(\mathrm{V})$ center appear as an appealing system to prevent dyes aggregation. After optimization, PCE up to $5.6 \%$ have been obtained with better results for compound 54. These performances were attributed to a better charge collection. These two examples show that the phosphole backbone can be used as $\pi$-conjugated linker and as anchoring group for the development of new dyes for DSSCs.
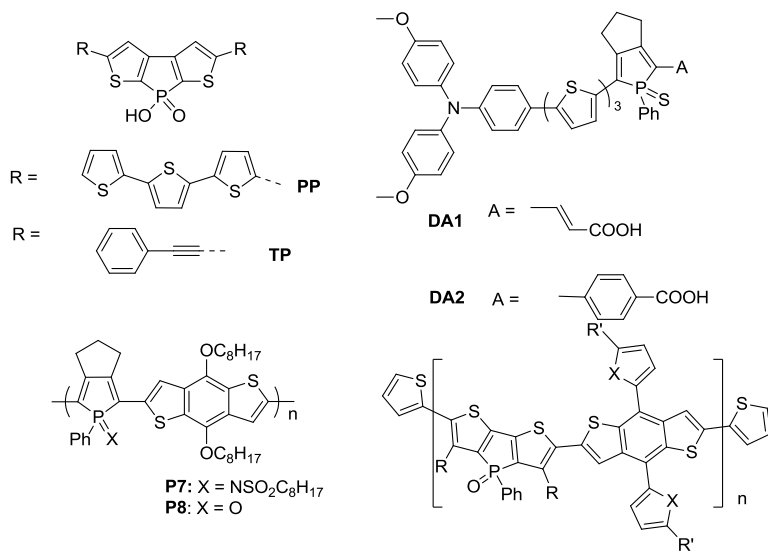

P9: $X=S$ P10: $X=S$
P10

Fig. 8: dithienophosphole based dyes for DSSC and phosphole polymers Organic Solar cells.

\subsection{As donors in organic photovoltaics}

In 2014 was published the first example of phosphole-based polymer for organic photovoltaics. P7 and P8 (Fig. 8) were based on benzodithiophene and either imidophosphole or oxophosphole. Modification at the $\mathrm{P}$ atom does not modify the optical properties. Both polymers were used as donors in blend with $\mathrm{PC}_{71} \mathrm{BM}$ acceptor and significantly better photovoltaic performances were achieved with the oxophosphole derivatives (P8: $\mathrm{J}_{\mathrm{sc}}=2.6 \mathrm{~mA} . \mathrm{cm}^{-2}, \mathrm{~V}_{\mathrm{oc}}=0.63 \mathrm{~V}, \mathrm{FF}=$ $0.40, \eta=0.65 \%$; P7: $\mathrm{J}_{\mathrm{sc}}=0.45 \mathrm{~mA} . \mathrm{cm}^{-2}, \mathrm{~V}_{\mathrm{oc}}=0.45 \mathrm{~V}, \mathrm{FF}=0.35, \mathrm{\eta}=$ $0.07 \%)$. These results show that P-substituents have a clear impact on the charge-generation efficiency and/or chargecarrier pathways in the blend. These pioneering results were recently overcome by the use of P9-10 (Fig. 8). ${ }^{76}$ In this case, the P-containing repeated unit is a dithienophosphole oxide that acts as electron deficient unit in donor-acceptor low-band gap polymer. Bulk heterojunction devices prepared by mixing the P9-10 donors with $\mathrm{PC}_{71} \mathrm{BM}$ acceptor allowed the authors to reach a PCE of $7.1 \%$ in the case of solar cells processed with 1,8-octanedithiol as additive (P9: $\mathrm{J}_{\mathrm{sc}}=13.2 \mathrm{~mA} . \mathrm{cm}^{-2}, \mathrm{~V}_{\mathrm{oc}}=0.87 \mathrm{~V}$, $\mathrm{FF}=0.53, \eta=6.10 \%$; P10: $\mathrm{J}_{\mathrm{sc}}=14.8 \mathrm{~mA} . \mathrm{cm}^{-2}, \mathrm{~V}_{\mathrm{oc}}=0.85 \mathrm{~V}, \mathrm{FF}=0.56$, $\eta=7.08 \%)$. The authors attribute this efficiency to the high polarizability of the oxophosphole moiety. This efficiency is close to the best efficiency reached for all organic devices and paves the way for highly efficient P-containing polymers for photovoltaic applications.

\subsection{Electrochemical cell}

In 2012 Baumgartner et al. designed discotic dendritic phospholes that form luminescent gels and liquid crystalline phases. ${ }^{77}$ In particular, they showed on compound $\mathbf{5 5}$ (Fig. 9) that oxidation allows tuning the colour and the photoluminescence of a simple electrochromic cell (ITO/55+NBu $\mathrm{NClO}_{4} /$ ITO). This was the first example of electrochromism on P-heterocycles. This concept was recently applied to derivative 56-57 (Fig. 9). This phospholeviologen analogs display very low reduction potential and the electrochromic behaviour could be demonstrated with a switch from the colourless dication of $\mathbf{5 6}$ to its blue mono-cationic form. ${ }^{78}$ 
This concept was further applied to multicolour electrochromic devices using the 3 stable redox states of $57 .{ }^{79}$ These devices are not OLED as there is no electroluminescence, but these studies show that the amphoteric redox properties of phosphole allow tuning their absorption/emission upon electrical stimuli.
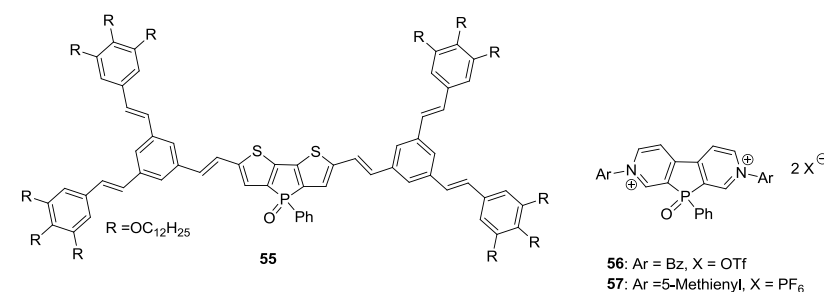

Fig. 9 : Phosphole derivatives used in electrochromic devices

\section{4-membered ring P-heterocycles}

\subsection{1,3-Diphosphacyclobutane-2,4-diyls}

Ito et al. recently reported the synthesis of air-stable Pheterocyclic biradicals, namely 1,3-diphosphacyclobutane-2,4diyls (Fig. 1 and 10). ${ }^{80}$ These compounds were first prepared by Niecke et al. $^{81}$ but its only when Ito et al. modified the substituent at the $\mathrm{P}$ atom that air stable compound could be prepared. In particular, the use of amino-substituted triazine allowed them to prepare $\mathbf{5 8}$ as an air-stable derivative with low oxidation potential. FET device $\left(\mathrm{Si} / \mathrm{SiO}_{2}\right.$ wafer with interdigitated $\mathrm{Au}$ bottom electrodes) using drop-casted $\mathbf{5 8}$ were prepared. The device exhibited $\mathrm{p}$-semi-conducting properties with low mobility $\left(2.310^{-8} \mathrm{~cm}^{2} \cdot \mathrm{V}^{-1} \cdot \mathrm{s}^{-1}\right)$ and an on/off ratio of 7 . The lack of intra-molecular interactions in the solidstate is a possible reason for this low activity. These characteristics are rather low compared to benchmark organic semi-conductors. However, this first example of P-containing OFET-active compound clearly shows that these derivatives can be interesting for this application. Considering the electron affinity of phosphine/phosphole oxide, the preparation of OFET with n-type characteristics is clearly a perspective for all these compounds. ${ }^{82}$

\subsection{Phosphete}

Recently, 1,2-dihydrophosphete derivatives (Fig. 1 and 10) were also introduced as new $\pi$-conjugated systems for optoelectronic applications. This unsaturated four-membered P-heterocycle appeared as an appealing skeleton to develop novel P-based emitters. Like in phosphine and phospholes, the pyramidal shape of the $P$ affords steric hindrance that prevents solid-state aggregation. A whole family of fluorophores based on this skeleton (59-61, Fig. 10) was prepared by Chen et al. ${ }^{83}$

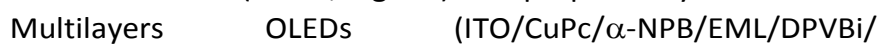
$\mathrm{BCP} / \mathrm{Alq}_{3} / \mathrm{LiF}$. All compounds displayed blue electroluminescence characteristic of the P-fluorophores. Efficiencies were higher when the compounds were doped in a matrix (CPB or DPVBi). This was attributed to moderate charge carrier mobility in the EML. In particular, devices prepared with 59 in a DPVBi matrix exhibited blue electroluminescence, good performances and current independent CIE coordinates.
This preliminary study paves the way for the development of efficient devices based on this new P-scaffold.

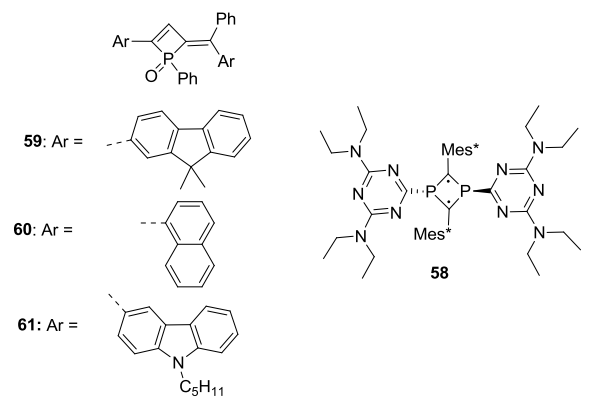

Fig. 10: Diphosphacyclobutane diradical DPCB used in FET device and phosphetes derivatives Phos1-3 for OLEDs

\section{Conclusions}

This review presents the main class of P-containing $\pi$ conjugated compounds used in electronic devices (mainly OLEDs). By far, the most widely studied class of organophosphorus derivatives in optoelectronics are the triarylphosphines used as ETL or hosts for triplet emitters in OLEDs. Their thermal stability, the high electron affinity of the oxophosphine moiety associated with the easy modification of the aryl substituents made the use of the triarylphosphines very popular. The second class of compounds which is also widely used are the phospholes. They were mainly studied as emitters in OLEDs (including WOLEDs). The incorporation of the phosphole fragment in the $\pi$-system allows obtaining solidstate emission due to the pyramidal shape of $P$ that prevents aggregation. Furthermore, the intrinsic low-band gap of phosphole allows obtaining compound with red-shifted absorption/emission compared to the phosphines. In addition to these two classes of P-derivatives, phosphazenes and phosphete derivatives have also been used in OLEDs.

In the case of the solar cells, the (thieno)phospholes appear as the most adapted P-backbone as it allows good light absorption due to its low HOMO-LUMO gap together with a good electron affinity and planarity that will favor charge transport in the solid-state. However, the examples of their use remain limited. Nevertheless, there are no theoretical limitations for the developments of these compounds for photovoltaic applications, including by replacing fullerenes as acceptor considering the excellent electron affinity of all phosphine oxide derivatives.

Finally, only one example of organophosphorus derivative for OFET application has been described to the best of our knowledge. Surprisingly, it is a p-type OFET based on an unusual diradical backbone structure, while the oxidized organophosphorus derivatives are widely used for their electron affinity. Here again, no technical limitation is responsible for the absence of P-derivatives. The recent development of highly planar P-derivatives and phosphahelicenes should give rise to new solid state organization and new physical properties interesting for the preparation of $n$-type OFETS or 3D-OLEDs, respectively. ${ }^{71,84,85}$ 
However, based on the variety of different P-scaffold described in the literature, ${ }^{7,86}$ new efficient P-derivatives for opto-electronic applications are still to be discovered.

\section{Acknowledgements}

This work is supported by the Ministère de la Recherche et de l'Enseignement Supérieur, the Institut Universitaire de France, the CNRS, the Région Bretagne, Chinese-French associated international laboratory in "Functional Organophosphorus Materials", the French National Research Agency (ANR)/Research Grants Council (RGC) Joint Research Scheme (ANR MOLMAT) and COST CM10302 (SIPS).

\section{Notes and references}

1 a) H. Shirakawa, Angew. Chem., Int. Ed. 2001, 40, 2574; b) A. G. MacDiarmid, Angew. Chem.,Int. Ed. 2001, 40, 2581;c) A. J. Heeger, Angew. Chem., Int. Ed. 2001, 40, 2591.

(a) M. Leclerc, J.-F. Morin in Design and Synthesis of Conjugated Polymers, Wiley-VCH: Weinheim, 2010 b) Y.Chujo in Conjugated Polymer Synthesis: Methods and Reactions; Wiley-VCH: Weinheim, 2011; c) T. A. Skotheim and J. R. Reynolds in Handbook of Conducting Polymers, 3nd ed. Eds.; CRC Press: Boca Raton, 2006; d) Müllen K. and Wegner G. in Electronic Materials: the Oligomer Approach, Wiley-VCH: Weinheim, 1998; Fichou D. in Handbook of Oligo- and Polythiophenes, Wiley-VCH: Weinheim, 1998. e) P. F. H. Schwab, J. R. Smith and J. Michael, Chem. Rev. 2005, 105, 1197;f) A. Mishra, C.-Q. Ma and P. Bäuerle, Chem. Rev. 2009, 109, 1141; g) R. E. Martin and F. Diederich, Angew. Chem. Int. Ed. 1999, 38, 1350; h) J. Roncali, Chem. Rev. 1992, 92, 711; i) F. M. J. Hoeben, P. Jonkheijm, E. W. Meijer and A. P. H. J. Schenning, Chem. Rev. 2005, 105, 1491; j) A. C. Grimsdale, K. L. Chan, R. E. Martin, P. G. Jokisz and A. B. Holmes, Chem. Rev. 2009, 109, 897;

a) K. Müllen and U. Scherf in Organic Light Emitting Devices, Wiley-VCH: Weinheim, 2006; b) C. Brabec, V. Dyakonov and U. Scherf in Organic Photovoltaics: Materials, Device Physics, and Manufacturing Technologies, Wiley-VCH: Weinheim, 2008; c) $\mathrm{H}$. Klauk in Organic Electronics: Materials, Manufacturing and applications, Wiley-VCH: Weinheim, 2006; d) S.-S. Sun, N. S. Sariciftci in Organic Photovoltaics: Mechanisms, Materials, and Devices, CRC Press: Boca Raton, 2005; e) Z. Bao and J. Locklin in Organic Field-Effect Transistors, CRC Press: Boca Raton, 2007.

a) S. Günes, H. Neugebauer and N. S. Sariciftci, Chem. Rev. 2007, 107, 1324; b) R. Kroon, M. Lenes, J. C. Hummelen, P. W. M. Blom and B. de Boer, Polym. Rev. 2008, 48; c) 531Y.-J. Cheng, S.-H.g Yang and C.-S. Hsu, Chem. Rev. 2009, 109, 5868; d) A. C. Grimsdale, K. L. Chan, R. E. Martin, P. G. Jokisz and A. B. Holmes, Chem. Rev. 2009, 109, 897; e) U. Mitschke and P.Baüerle, J. Mater. Chem. 2000, 10, 1471; f) A. P. Kulkarni, C. J. Tonzola, A. Babel and S. A. Jenekhe, Chem. Mater. 2004, 16, 4556; g) C.-T. Chen, Chem. Mater. 2004, 16, 4389; h) A. R. Murphy and J. M. J. Fréchet, Chem. Rev. 2007, 107, 1066; i) Y. Wen and Y. Liu, Adv. Mater. 2010, 22, 1331

a) J. Roncali, Chem. Rev. 1997, 97, 173; b) P. M. Beaujuge and J. R. Reynolds, Chem. Rev. 2010, 110, 268.

${ }^{6}$ A. B: Padmaperuma, G. Schmett, D. Fogarty, N. Washton, S. Nanayakkara, L. Sapochak, K. Asworth, L. Madrigal and B: Reeves, C. W. Spangler, Mater. Res. Soc. Sym. Proc. 2001, 621, Q3.9.1.

7 R. Réau and T. Baumgartner, Chem. Rev. 2006, 106, 4691

${ }^{8}$ B. Schäfer, E. Öberg, M. Kritikos and Sascha Ott, Angew. Chem. Int. Ed. 2008, 47, 8228 .
${ }^{9}$ R. C. Smith and J. D. Protasiewicz , Eur. J. Inorg. Chem., 2004, 5, 998.

${ }^{10}$ For specific reviews on these devices, see : (a) B. C. Thompson and J.M.J. Fréchet, Angew. Chem. Int. Ed. 2008, 47, 58. (b) J. L. Delgado, P.-A. Bouit, S. Fillipone, M.A. Herranz and N. Martín, Chem. Commun. 2010, 46, 4853. (c) M. Graetzel, Inorg. Chem 2005, 44, 6841. (d) K. Müllen, U. Scherf, (Eds:), Organic Light Emitting Devices: Synthesis Properties and Applications, Wiley-VCH, Weinheim, Germany 2006; (e) K. Müllen, G. Wegner, Electronic Materials: The Oligomer Approach; Wiley-VCH, Weinheim, 1998; (f) A. Mishra, C.-Q. Ma, J. L. Segura, P. Bauerle, Handbook of Thiophene-Based Materials 2009, 1, 1.

11 G.C. Giordan, J.H. Moore, J.A.Tossell and W. Kaim J Am Chem Soc 1985, 107, 5600

${ }^{12}$ S. Yamaguchi, S. Akiyama and K. Tamao J Organomet Chem 2002, 646, 277

13 S. O. Jeon and J. Y. Lee, J: Mater. Chem. 2012, 22, 4233.

14 M. Y. Ha and D. G. Moon, Synth. Met. 2008, 158, 617

15 A. L. V. Ruden, L. Cosimbescu, E. Polikarpov, P. K. Koech,J. S. Swensen, L. Wang, J. T. Darsell and A. B. Padmaperuma, Chem. Mater. 2010, 22, 5678.

16 T. Oyamada, H. Sasabe, C. Adachi, SeiS.ichiro Murase T. Tominaga and C. Maeda, Appl. Phys. Lett. 2005, 86, 033503.

17 S. O. Jeon, K. S. Yook, C. W. Joo and J. Y. Lee, J. Mater. Chem. 2009, 19, 5940.

18 S. E. Jang, C. W. Joo and J. Y. Lee, Thin Solid Films 2010, 519, 906.

19 S. O. Jeon, K. S. Yook, C. W. Joo and J. Y. Lee, Appl. Phys. Lett 2009, 94, 013301

20 X. Cai, A. B. Padmaperuma, L. S. Sapochak, P. A. Vecchi and P. E. Burrows, Appl. Phys. Lett. 2008, 92, 083308.

21 S. O. Jeon, K. S. Yook, B. D. Chin, Y. S. Park and J. Y. Lee, Sol. Energy Mater. Sol. Cells 2010, 94, 1389.

22 S. O. Jeon and J. Y. Lee, Sol. Energy Mater. Sol. Cells 2011, 95, 2011.

${ }^{23}$ S. O. Jeon, S. E. Jang, H. S. Son and J. Y. Lee, Adv. Mater. 2011 23, 1436 .

${ }^{24}$ Y. Chi and P.T. Chou, Chem. Soc. Rev., 2010, 39, 638

${ }^{25}$ P. E. Burrows, A. Padmaperuma, L. S. Sapochak, P. Djurovich, and M. E. Thompson, Appl. Phys. Lett.,2006, 88, 183503.

26 H. S. Son, C. W. Seo and J. Y. Lee, J. Mater. Chem. 2011, 21 5638

27 Y. J. Cho and J. Y. Lee, Chem.-Eur. J. 2011, 17, 11415

28 S. O. Jeon, S. E. Jang, H. S. Son and J. Y. Lee, Adv. Mater. 2011, 23, 1436

29 K. S. Yook and J. Y. Lee, Org. Electron. 2011, 12, 1711.

30 C. Han, Z. Zhang, H. Xu, G. Xie, J. Li, Y. Zhao, Z. Deng, S. Liu and P. Yan, Chem. Eur. J. 2013, 19, 141;

31 S. Shao, J. Ding , T. Ye , Z. Xie , L. Wang, X. Jing and F. Wang, Adv. Mater. 2011, 23, 3570.

32 J. Zhuang, W. Li, W. Su, M. Zhou and Z. Cui, New J.Chem. 2014, 38,650 .

33 S. Gong, Y.-L. Chang, K. Wu, R. White, Z.-H. Lu,. D. Song and C. Yang, Chem. Mater. 2014, 26, 1463.

34 S. E. Jang, C. W. Joo and J. Y. Lee, Thin Solid Films, 2010, 519, 906.

35 S. O. Jeon, K. S. Yook, C. W. Joo and J. Y. Lee, Org. Electron., 2010,11, 881.

36 S. Thiery, D. Tondelier, B. Geffroy, E. Jacques, M. Robin, R. Métivier, O. Jeannin, J. Rault-Berthelot and C. Poriel Org. Lett. 2015, 17,4682 .

37 Y. J. Cho and J. Y. Lee, J. Phys. Chem. C 2011, 115, 10272. 
38 Y. Tao, J. Xiao, C. Zheng, Z. Zhang, M. Yan, R. Chen, X. Zhou, H. Li, Z. An, Z. Wang, H. Xu, andW. Huang, Angew. Chem. Int. Ed. 2013, 52, 10491

C 2014, 118, 7569.

C Liu, Y. Gu, Q. Fu, N. Sun, C. Zhong, D. Ma, J. Qin and C. Yang, Chem. Eur. J. 2012, 18, 13828.

41 C. Liu, Y. Li, Y. Li, C. Yang, H. Wu, J. Qin and Y. Cao, Chem. Mater. 2013, 25, 3320.

S. Shao, J. Ding, L. Wang, X. Jing and F. Wang, J. Am. Chem. Soc. 2012, 134, 15189.

S. Shao, J. Ding, L. Wang, X. Jing and F. Wang, J. Am. Chem. Soc. 2012, 134, 20290.

44 Y. Zhao, L. Duan, X. Zhang, D. Zhang, J. Qiao, G. Dong and L. Wang, Y. Qiu, RSC Adv. 2013, 3, 21453.

${ }^{45}$ J. H. Lee, S. H. Cheng, S. J. Yoo, H. Shin, J. H. Chang, C.I. Wu, K.T. Wong and J. J. Kim, Adv. Funct. Mater. 2015, 25, 361

${ }^{46}$ K. Goushi and C. Adachi, Applied Phys. Lett. 2012, 101, 023306.

${ }^{47}$ Y. Tao , K. Yuan, T. Chen , P. Xu , H. Li , R. Chen, C. Zheng, L. Zhang, and W. Huang Adv. Mater. 2014, 26, 7931-7958

48 P. M. Blonsky, D. F. Shriver, P. Austin and H. R. J. Allcock, J. Am. Chem. Soc. 1984, 106, 6854.

${ }_{49}$ W. Xiang, Y. Zhou, X. Yin, X. Zhou, S. Fang and Y. Lin, Electrochim. Acta 2009, 54, 4186

50 S. T. Feh, S.-H. A. Lee, S. Pursel, J. Basham, C. A. Grimes, M. W. Horn, T. E. Mallouk and H.A. Allcock, J. Power Sources 2011, 196, 5223.

51 S. M. Pursel, J. Basham, C. A. Grimes, M. W. Horn, H. R. Allcock and T. E. Mallouk, J Phys. Chem. C 2010, 114, 15234.

52 a) H. J. Bolink, E. Barea, R. D. Costa, E. Coronado, S. Sudhakar, C. Zhen and A. Sellinger, Org. Elect. 2008, 9, 155; b) H. J. Bolink, S. G. Santamaria, S. Sudhakar, C. Zhen and A. Sellinger, Chem. Comm. 2008, 618

${ }^{53}$ L. Bauge, G. Vériot, G. Franc, R. Deloncle, A.-M. Caminade and J.P. Majoral, Tetrahedron 2006, 62, 11891.

54 M. S. Soh, S. A. G. Santamaria, E. L. Williams, M. Pérez-Morales, H. J. Bolink and A. Sellinger, J. Polym. Sci. B.: Polym. Phys. 2011, 49, 531.

55 P. Schrögel, M. Hoping, W. Kowalsky, A. Hunze, G. Wagenblast, C. Lennartz and P. Strohriegl, Chem. Mater. 2011, 23, 4947.

56 H. Sasabe, J.-i. Takamatsu, T. Motoyama, S. Watanabe, G. Wagenblast, N. Langer, O. Molt, E. Fuchs, C. Lennartz and J. Kido, Angew. Chem. Int. Ed. 2010, 22, 5003.

${ }^{57}$ M. Hissler, P. W. Dyer and R. Réau, Coord. Chem. Rev. 2003, 244, 1

${ }^{58}$ L. Nyulaszi, O. Holloczki, C. Lescop, M. Hissler and R. Réau. Org. Biomol. Chem. 2006, 4, 996.

59 H. Tsuji, K. Sato, Y. Sato and E. Nakamura, J. Mater. Chem. 2009, 19, 3364.

${ }_{60}$ H. Tsuji, K. Sato and E. Nakamuro, Chem. Asian. J. 2010, 5, 1294.

61 Y. Matano, A. Saito, Y. Suzuki, T. Miyajima, S. Akiyama, S. Otsubo, E. Nakamoto, S. Aramaki and H. Imahori, Chem. Asian J. 2012, 7, 2305.

${ }^{62}$ C.-H. Lin, C.-W. Hsu, J.-L. Liao, Y.-M. Cheng, Y. Chi, T.-Yi Lin, M.-W. Chung, P.-T. Chou, G.-H. Lee, C.-H. Chang, C.-Y. Shih and C.-L. Ho J. Mater. Chem. 2012, 22, 10684.

63 C. Fave, T.-Y. Cho, M. Hissler, C.-W. Chen, T.-Y. Luh, C.-C. Wu and R. Réau, J. Am. Chem. Soc. 2003, 125, 9254.

64 H.-C. Su, O. Fadhel, C.-J. Yang, T.-Y. Cho, C. Fave, M. Hissler, C.C. Wu and R. Réau, J. Am. Chem. Soc. 2006, 128, 983.

65 D. Joly, D. Tondelier, V. Deborde, B. Geffroy, M. Hissler and R. Réau, New J. Chem. 2010, 34, 1603.

66 R.-F. Chen, R. Zhu, Q.-L. Fan and W. Huang, Org. Lett. 2008, 10, 2913.
67 R. Kondo, T. Yasuda, Y. S. Yang, J. Y. Kim and C. Adachi, J. Mater. Chem. 2012, 22, 16810.

68 O. Fadhel, M. Gras, N. Lemaitre, V. Deborde, M. Hissler, B. Geffroy and R. Réau, Adv. Mater. 2009, 21, 1261.

69 D. Joly, D. Tondelier, V. Deborde, W. Delaunay, A. Thomas, K. Bhanuprakash, B. Geffroy, M. Hissler and R. Réau, Adv. Funct. Mater. 2012, 22, 567.

${ }_{70}$ H. Chen, W. Delaunay, L. Yu, D. Joly, Z. Wang, J. Li, Z. Wang, C. Lescop, D. Tondelier, B. Geffroy, Z. Duan, M. Hissler, F. Mathey and R. Réau, Angew. Chem. Int. Ed. 2012, 51, 214.

71 P.-A Bouit, A. Escande,; R. Szúcs, D.Szieberth,; C. Lescop, L. Nyulászi,; M. Hissler, R. Réau, J. Am. Chem. Soc. 2012, 134, 6524.

${ }^{72}$ F. Riobé, R. Szűcs, P.-A. Bouit, D. Tondelier, B. Geffroy, F. Aparicio, J. Buendía, L. Sánchez, R. Réau, L. Nyulászi and M. Hissler, Chem. Eur. J. 2015, 21, 6547.

${ }^{7}$ A. Kira, Y. Shibano, S. Kang, H. Hayashi, T. Umeyama, Y. Matano and H. Imahori, Chem. Lett. 2010, 39, 448450.

${ }^{74}$ L. Zhang, J. M. Cole, ACS Appl. Mater. Interfaces, 2015, 7, 3427.

${ }^{75}$ Y. Matano, Y. Hayashi, H. Nakano and H. Imahori Heteroatom. Chem. 2014, 25, 533.

${ }^{76}$ K. H. Park, Y. J. Kim, G. B. Lee, T. K. An, C. E. Park, S.-K. Kwon and Y.-H. Kim Adv. Func. Mater. 2015, 25, 3991.

77 C. Romero-Nieto, M. Marcos, S. Merino, J. Barberá, T. Baumgartner and J. Rodríguez-López Adv. Funct. Mater. 2011, 21, 4088.

${ }^{78}$ M. Stolar, J. Borau-Garcia, M. Toonen and T. Baumgartner J. Am. Chem. Soc., 2015, 137, 3366.

${ }^{79}$ C. Reus, M. Stolar, J. Vanderkley, J. Nebauer and T. Baumgartner J. Am. Chem. Soc., 2015, 137, 11710.

${ }^{80}$ S. Ito, Y. Ueta, T. Thi Thu Ngo, M. Kobayashi, D. Hashizume, J. Nishida, Y. Yamashita and K. Mikami, J. Am. Chem. Soc. 2013, 135 , 17610.

${ }^{81}$ E. Niecke, A. Fuchs, F. Baumeister, M. Nieger and W. W. Schoeller Angew. Chem. Int. Ed. 1995, 34, 555.

82 mobility of electrons has been reported for oxophospholes, but no transistors have been prepared, see references 59 or 84a.

${ }^{83}$ H. Chen, S. Pascal, Z. Wang, P.-A. Bouit, Z. Wang, Y. Zhang, D. Tondelier, B. Geffroy, R. Réau, F. Mathey, Z. Duan and M. Hissler, Chem. Eur. J. 2014, 20, 9784.

${ }^{84}$ (a) Y. Matano, A. Saito, T. Fukushima, Y. Tokudome, F. Suzuki, D. Sakamaki, H. Kaji, A. Ito, K. Tanaka and H. Imahori Angew. Chem. Int. Ed. 2011, 50, 8016. (b) Y. Ren and T. Baumgartner, J. Am. Chem. Soc. 2011, 133,1328 (c) A. Furakawa, H. Yamada and S. Yamaguchi, Angew. Chem.Int. Ed. 2008, 47, 5582.

${ }^{85}$ (a) N. Saleh, C. Shen and J. Crassous, Chem. Sci. 2014, 5, 3680-

3694. (b) M. J. Narcis and N. Takenaka, Eur. J. Org. Chem. 2014, 2134. (c) P. Aillard, A. Voituriez and A. Marinetti, Dalton Trans.

2014, 43, 15263.

${ }^{86}$ F. Mathey, Angew. Chem. Int. Ed. 2003, 42, 1578. 